\title{
Congenital Rubella in Schoolchildren and Adolescents
}

\author{
JILL M. FORREST and MARGARET A. MENSER \\ From the Children's Medical Research Foundation, Royal Alexandra Hospital for Children, \\ Sydney, Australia
}

Forrest, Jill M., and Menser, Margaret A. (1970). Archives of Disease in Childhood, 45, 63. Congenital rubella in schoolchildren and adolescents. Forty-one cases of congenital rubella in schoolchildren and adolecents are reported. Most children had multiple defects, the nature and severity of which could not be correlated with the reported time during pregnancy of the maternal rubella infection.

This study was undertaken to assess the status of adolescent and school age children with congenital rubella in New South Wales.

\section{Cases and Methods}

Sixty-two subjects in the age-group 5-19 years were interviewed. These patients were located from hospital records, from schools or classes for deaf or partiallysighted children, and from institutions for crippled, retarded, or handicapped children. A half-day interview with the patient and mother was carried out. This included a full physical examination of the child with fundoscopy.

Patients were considered to have congenital rubella if rubella chorioretinopathy was present; if in the presence of a clinical history of rubella during pregnancy, one or more of the following 'classical' defects occurred: deafness, ocular lesions, congenital cardiovascular system abnormalities, or central nervous system defects; if 2 of the above defects followed contact without clinical rubella during pregnancy; or if 3 of the above defects were present with no history of rubella during pregnancy.

Heights and weights were compared with the centile curves for Australian children of the same age and sex, (Australian Institute of Anatomy, 1957). Deafness was classified according to the standards of Keir (1965), on the basis of audiograms which were in most cases kindly supplied by the Commonwealth Acoustic Laboratory. The hearing loss was described as severe when the average loss was greater than $\mathbf{4 0}$ decibels for the speech frequencies (500 to 4000 cycles per second); and moderate when the average loss was 15-40 decibels. Speech was assessed by the examining physician; defects were described as mild when enunciation was defective, moderate when enunciation was difficult or sentence formation was affected, and severe when single words only were used.

Urinalysis, micro-urine, chest $x$-ray, ECG, blood urea, blood sugar, and $\mathrm{Hb}$ estimations were performed

Received 30 May 1969. for each patient. Urine and throat swabs were cultured for rubella virus. Rubella-virus haemagglutinationinhibition antibody (HI) titres were estimated for patients and their mothers (Kenrick et al., 1968).

\section{Results}

General. Of the 62 patients interviewed, 41 ( 16 boys, 25 girls) had definite congenital rubella. The clinical features of these 41 patients are set out in Table $I$. Their ages ranged from 5 years 11 months to 19 years 2 months. 36 were born in the months April to August inclusive. All except one were born in Australia; the exception was born in England, and travelled to Australia in the first month of life. The parents of one child were Italian, one had a Maltese father, and one a Swedish mother.

The mother. The average maternal age at the time of delivery was 25 years, with a range of 16-49 years. The ages of 3 mothers were not known. 37 mothers had had definite attacks of rubella (Table I); of these 5 had received $\gamma$-globulin. The stages of pregnancy at which the attacks occurred ranged from 2 to 12 weeks after the last menstrual period. The timing of the maternal infection was based on the mother's retrospective recollections, together with obstetric or paediatric hospital records, which were compiled close to the time of infection. Such records were available in 34 cases. In one case, the timing was stated only as 'early in pregnancy'. The reliability of the mother's recollection was doubtful in 2 cases only. One mother had no history of rubella or rubella contact during her pregnancy and 3 had contact with rubella, without a clinical attack, all 3 having received prophylactic $\gamma$-globulin 
TABIE

Features of 41 Childref

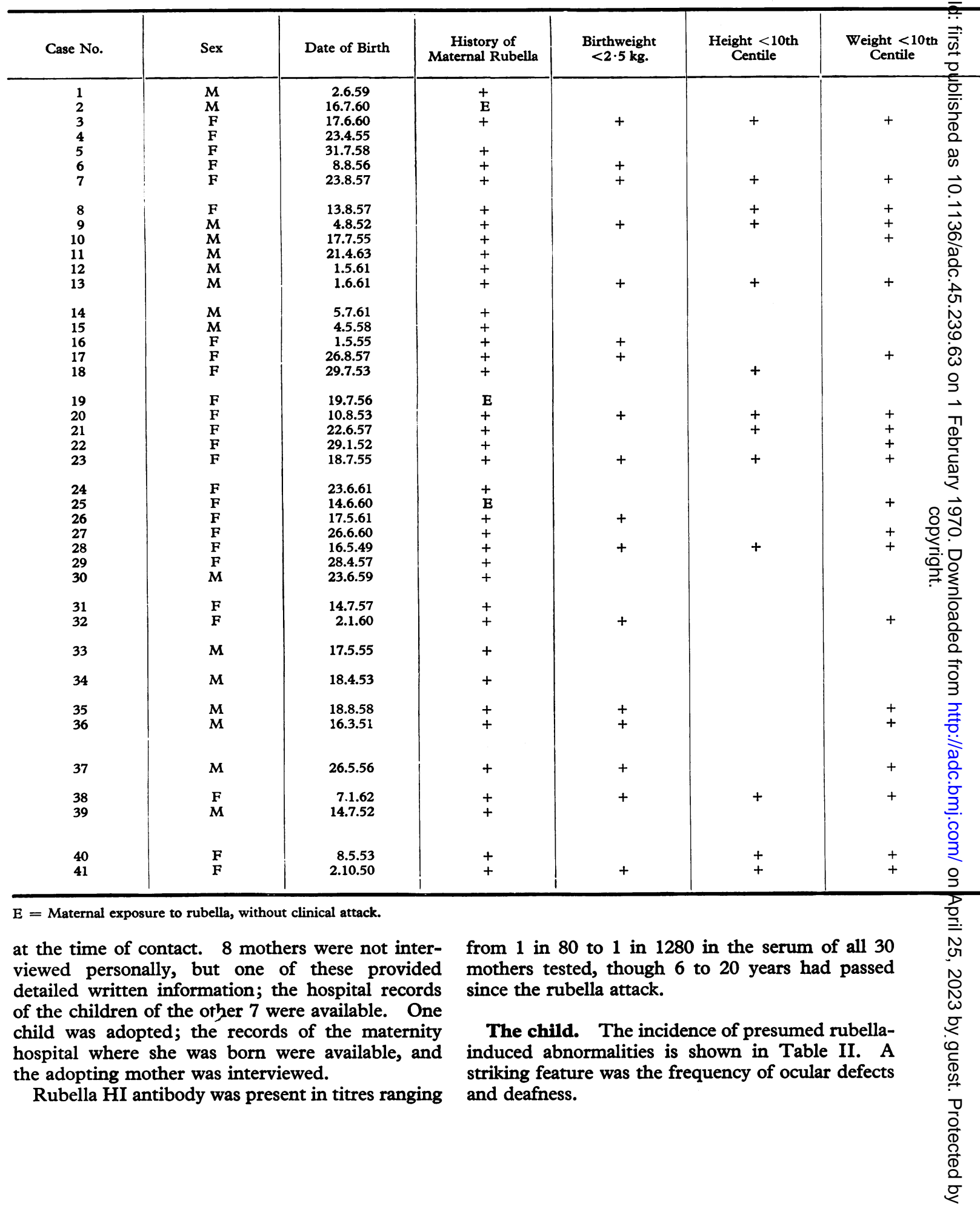




\begin{tabular}{|c|c|c|c|c|c|c|c|}
\hline Ocular Defect & $\begin{array}{c}\text { Congenital } \\
\text { Heart Disease }\end{array}$ & Deafness & Speech Defect & $\begin{array}{c}\text { Central } \\
\text { Nervous } \\
\text { System Defect }\end{array}$ & Dental Defect & $\begin{array}{l}\text { Dermatogly- } \\
\text { phic Changes }\end{array}$ & Skeletal and Other Defects \\
\hline+ & + & + & + & & + & & \\
\hline+ & + & + & + & & & + & Undescended testes \\
\hline+ & + & & + & + & & + & Talipes equinovarus \\
\hline+ & + & & & + & & & Diabetes mellitus \\
\hline+ & 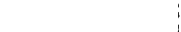 & + & + & & & & Depressed sternum \\
\hline+ & + & + & & & + & + & \\
\hline+ & + & + & & & + & & $\begin{array}{l}\text { High palate; pes cavus; } \\
\text { elfin facies }\end{array}$ \\
\hline+ & & + & + & + & + & + & Inturned toes \\
\hline+ & & & + & + & + & & High palate \\
\hline+ & 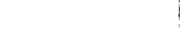 & + & + & & + & + & Pes cavus \\
\hline+ & & + & + & & & $\vdots$ & \\
\hline & & + & + & & + & + & \\
\hline$\div$ & + & & + & + & + & & $\begin{array}{l}\text { Talipes calcaneovalgus; } \\
\text { undescended testes }\end{array}$ \\
\hline+ & & + & + & & & & \\
\hline+ & + & + & & & & + & High palate; clinodactyly \\
\hline+ & + & + & + & & + & & High palate \\
\hline+ & & + & + & & & & Hioh palate hrochedoctuln \\
\hline+ & & & & + & + & + & $\begin{array}{l}\text { High palate; brachydactyly } \\
\text { fifth finger }\end{array}$ \\
\hline & & + & + & + & & + & \\
\hline $\begin{array}{l}+ \\
+\end{array}$ & + & + & $\begin{array}{l}+ \\
+\end{array}$ & $\begin{array}{l}+ \\
+\end{array}$ & & + & $\begin{array}{l}\text { High palate; sternal deformity } \\
\text { Clinodactyly }\end{array}$ \\
\hline+ & & + & + & + & & & High palate \\
\hline+ & & + & : & + & + & & $\begin{array}{l}\text { High palate, micrognathia, } \\
\text { scoliosis, clinodactyly }\end{array}$ \\
\hline+ & & $T$ & + & & & + & Clinodactyly \\
\hline+ & + & + & & & + & 1 & Clinodactyly \\
\hline & + & + & + & & & & Clinodactyly; elfin facies \\
\hline+ & + & & + & + & & & 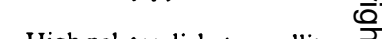 \\
\hline+ & & + & + & & + & & High palate; diabetes mellitus $\underset{?}{\vec{P}}$ \\
\hline+ & & + & & & & & $\begin{array}{l}\text { High palate; sternal deformity; } \\
\text { carotid bruits }\end{array}$ \\
\hline+ & & + & + & + & + & & Gluten intolerance \\
\hline+ & + & & & & + & + & $\begin{array}{l}\text { High palate; pes cavus; } \\
\text { clinodactyly; elfin facies }\end{array}$ \\
\hline+ & + & - & & & & + & $\begin{array}{l}\text { High palate; undescended } \\
\text { testes }\end{array}$ \\
\hline+ & & + & & & & & $\begin{array}{l}\text { Pes cavus; clinodactyly; } \\
\text { Raynaud's disease }\end{array}$ \\
\hline+ & & + & + & & & + & Undescended testes \\
\hline+ & & + & + & & ; & & $\begin{array}{l}\text { Valgus deformity of elbows; } \\
\text { pes cavus; undescended } \\
\text { testes }\end{array}$ \\
\hline+ & & + & + & & & + & $\begin{array}{l}\text { High palate; sternal deformity; } \\
\text { syndactyly of toes }\end{array}$ \\
\hline+ & & + & + & & & & Elfin facies \\
\hline+ & & & & & & + & $\begin{array}{l}\text { Talipes equinovarus; sternal } \\
\text { deformity; bifid uvula; high } \\
\text { palate; clinodactyly }\end{array}$ \\
\hline+ & & & & & & + & Elfin facies \\
\hline+ & & + & + & & & + & High palate; sternal deformity \\
\hline
\end{tabular}

Five children had only one classical defect; 3 of these had ocular defects, and 2 were deaf. 18 had 2 classical defects, the most common combination being deafness and ocular defects in 13 cases. 18 had 3 or more classical defects, 8 children having the classical rubella triad of deafness, ocular defects, and congenital heart disease. If other defects such as low birthweight, neonatal difficulties, small stature, and skeletal anomalies were included, only one child (Case 29) with deafness would have had a single defect (Table I).

Early history. Seventeen $\left(41_{/ 0}^{\circ}\right)$ had a birthweight of less than $2.5 \mathrm{~kg}$.; only 2 of these were more than 2 weeks' premature for dates. 7 were treated for prematurity and 3 others required 
TABLE II

Frequency of Rubella-induced Abnormalities in 41 Children

\begin{tabular}{|c|c|c|c|c|c|c|}
\hline \multicolumn{5}{|c|}{ Defects } & No. & $\%$ \\
\hline $\begin{array}{l}\text { Ocular defects } \\
\text { Deafness } . \\
\text { Congenital heart } \\
\text { Central nervous sy } \\
\text { Low birthweight } \\
\text { Neonatal difficulti } \\
\text { Skeletal defects } \\
\text { Small stature } \\
\text { Dental defects } \\
\text { Dermatoglyphic cl }\end{array}$ & $\begin{array}{l}\ldots \\
\text { disease } \\
\text { system } \\
\text { ies } \\
\ldots \\
\ldots \\
\text { changes }\end{array}$ & $\begin{array}{l}\cdots \\
\cdots \\
\text { invo } \\
\cdots \\
\cdots \\
\cdots \\
\cdots\end{array}$ & $\begin{array}{l}\cdots \\
\cdots \\
\cdots \\
\text { ment } \\
\ldots \\
\ldots \\
\ldots \\
\ldots \\
\ldots\end{array}$ & $\begin{array}{l}\cdots \\
\cdots \\
\cdots \\
\cdots \\
\cdots \\
\cdots \\
\cdots \\
\cdots\end{array}$ & $\begin{array}{l}37 \\
31 \\
15 \\
13 \\
17 \\
14 \\
27 \\
22 \\
16 \\
18\end{array}$ & $\begin{array}{l}90 \\
76 \\
37 \\
32 \\
41 \\
34 \\
66 \\
54 \\
39 \\
44\end{array}$ \\
\hline
\end{tabular}

oxygen at birth or in the first days of life. Of those with birthweights greater than $2.5 \mathrm{~kg}$., 2 had neonatal purpura, with thrombocytopenia in 1 case (platelets 60,000/cu.mm.). Another was jaundiced during the first 2 weeks of life.

During the first year of life, feeding difficulties or failure to thrive occurred in 13; in 2 of these, the failure to thrive was attributed to congenital heart disease, with congestive cardiac failure in 1 infant. In another 2 patients, recurrent respiratory infections were a feature.

General physical development. At the time of interview, 22 patients ( $54 \%$ ) were below the 10th centile for height or weight or both (Table I). 9 of these were below the third centile for both height and weight. 5 patients had the typical 'elfin facies', previously described (Dods, 1951).

Central nervous system. Ten children were severely mentally retarded, 7 being institutionalized. 4 of these 10 suffered from epilepsy. One other had had a single grand mal fit at the time of puberty. 4 were regarded as excitable or 'highly strung'. One had an auditory perceptual defect. 8 had varying degrees of spasticity, ranging from spastic quadriplegia to generalized hypertonia.

Those patients not retarded seemed normally distributed for mental ability (the highest recorded IQ being 139), and most were coping well with their disabilities. All except 2 attended classes for handicapped children. The oldest was employed doing domestic work, having completed 2 years of secondary education.

Ocular defects. A total of 37 patients (90\%) had ocular defects. 16 had typical rubella cataracts; in 11 this defect was bilateral. 4 of these 16 also had rubella chorioretinopathy. In one patient, a well-documented unilateral cataract had apparently been spontaneously absorbed by the age of 13 years, though the eye remained sightless. The 11 patients with bilateral cataracts had had a total of 51 operations. Of these, 4 patients were considered blind, and the vision of the other 7 was poor. 2 of the unilateral cataracts had been extracted, with poor results.

Two patients had congenital bilateral glaucoma; one of these had unilateral retinopathy with normal vision, the other had bilateral corneal opacities, which had not cleared, and her vision was poor. 3 patients had had their strabismus corrected, and one further patient was found to have a squint at the time of interview; all 4 of these patients had bilateral rubella chorioretinopathy and satisfactory vision. One patient had congenital bilateral nystagmus as the sole ocular defect, and another had had blocked tear ducts at birth.

A total of 22 patients had typical rubella chorioretinopathy. In 13, this was the only ocular defect, and did not cause any visual impairment.

Cardiovascular system. Fifteen patients (37\%) had congenital cardiovascular defects. The diagnosis had been proven at operation or cardiac catheterization in all except one patient (Case 32), who had a probable ventricular septal defect.

Eleven had had ligation of a persistent ductus arteriosus, with residual defects in 3 patients viz. one with pulmonary valve stenosis, one with aortic valve stenosis, and one with a ventricular septal defect. Ages at ligation varied from 3 months to 5 years, and in 2 infants pre-operative congestive cardiac failure had occurred. Of the other 4, one patient had pulmonary valve stenosis, not requiring operation, one had tetralogy of Fallot with secondary polycythaemia, one had mild aortic valve stenosis, and one had a probable ventricular septal defect.

Six patients had cardiac murmurs, considered innocent after investigation earlier in life. At the time of examination, no murmurs were detected in any of these 6 children. Two other patients had systolic ejection murmurs, considered innocent at the time of interview.

Additional points of interest were the findings of various systolic bruits. Case 4 had bruits over both femoral arteries and over the anterior abdominal wall, $2 \cdot 5 \mathrm{~cm}$. to the left of the umbilicus. Case 10 had a bruit over the left renal artery, without hypertension; he also had a systolic murmur, considered innocent by the cardiologist. Another had bruits over both carotid arteries, and one had a history suggestive of Raynaud's disease. 
Hearing and speech defects. Thirty-one patients (76\%) had a sensorineural hearing loss. In 10 patients, the deafness had been detected in the first year of life, in 14 before the child's third birthday, and by the age of 9 years in the remaining 7. This last group included those with milder hearing losses, as well as some in whom the diagnosis was difficult, due to associated mental retardation.

There were 27 patients with severe bilateral deafness, 3 with severe deafness in one ear and moderate deafness in the other, and one patient with moderate bilateral deafness. One patient had had progression of her deafness, due to middle ear infections. Another had had a left mastoidectomy.

Speech defects were severe in 14, moderate in 3, and mild in 6 of the deaf patients. 4 other patients who were not deaf had severe speech defects associated with mental retardation. 8 deaf patients had no speech defect; 4 of these patients were those with only moderate deafness, and the other 4 were patients with 'flat' audiograms who, though their deafness was severe, had some residual hearing at all frequencies.

Other defects. Twenty-seven children (66\%) had minor skeletal defects, which are listed in Table I. Of interest was the presence of only two phalanges in the right fifth finger of Case 18. This incidence of skeletal defects is much higher than in other reported studies, and comparison with a normal control group is needed before the defects can be considered rubella-induced.

Undescended testes had been present in 4 out of 16 boys ( $25 \%$ ).

Two patients had diabetes mellitus and are reported in detail elsewhere (Forrest, Menser, and Harley, 1969). Case 28 developed diabetes at the age of 18 months and was taking 53 units of insulin daily at the time of interview; her maternal great-aunt had had diabetes. Case 4 developed diabetes at the age of 12 years and was taking 96 units of insulin at the time of interview. Her paternal great-aunt had had diabetes mellitus. There was a family history of diabetes mellitus in 16 of the patients (39\%).

One patient (Case 31) had developed pale bulky stools at the age of 19 months and had improved with a gluten-free diet, which was continued for 2 years.

Sixteen patients $(39 \%)$ had dental abnormalities, which included delayed eruption, excessive caries, and deformities such as peg teeth and pointed teeth. 6 had brown staining of the teeth, often associated with a history of ingestion of tetracyclines in the early months of life. One had hypoplasia of the mandible.

Eighteen patients $(44 \%)$ had dermatoglyphic abnormalities; 5 had significant elevation of the axial triradius; 4 had 8 or 9 digital whorl patterns, and 10 had abnormal palmar creases, either simian lines, Sydney lines (Purvis-Smith and Menser, 1968), or both.

No abnormalities were detected in the routine haematological and biochemical tests. 3 patients with congenital heart disease had ECG changes.

In no case could the rubella virus be isolated from urine or throat swab. Rubella HI antibody was detected in 35 of the 36 patients tested-in the 13 with a history of postnatal rubella, the range of titres was similar to those without a history of a postnatal attack.

Relation between time of maternal infection and fetal defects. If the number of major defects in individual patients is compared with the reported time of infection of the mother, there was no significant difference between those whose infection occurred 2 weeks, 6 weeks, and 10 weeks after the last menstrual period; and 2 of the 4 following infections at 12 weeks had triple defects. There were no cases of infection later than 12 weeks in pregnancy.

In the Fig., the major defects have been plotted against the reported time of attack of or contact with rubella in the mother's pregnancy. The incidence of low birthweight and cardiovascular defects was greatest after infection in the first 4 weeks, but congenital heart disease still occurred after infection at 12 weeks. It is of interest that deafness followed attacks at any time, and was not more common when the attack occurred in the third month. Involvement of the central nervous system also followed attacks at any time.

The 4 patients whose mothers had subclinical rubella were just as severely affected as those whose mothers had a clinical attack; $\gamma$-globulin apparently gave no protection.

Comparison with adult patients. The present group was compared with the adult group reported by Menser, Dods, and Harley (1967), and the results are summarized in Table III. It is of interest that the incidence of low birthweight and small stature are so directly comparable.

In the younger group, the proportion with ocular defects was significantly greater than in the adult group $\left(x^{2}=12 \cdot 8, p<0 \cdot 0005\right)$ as was the proportion with minor skeletal defects $\left(x^{2}=6 \cdot 0\right.$, 


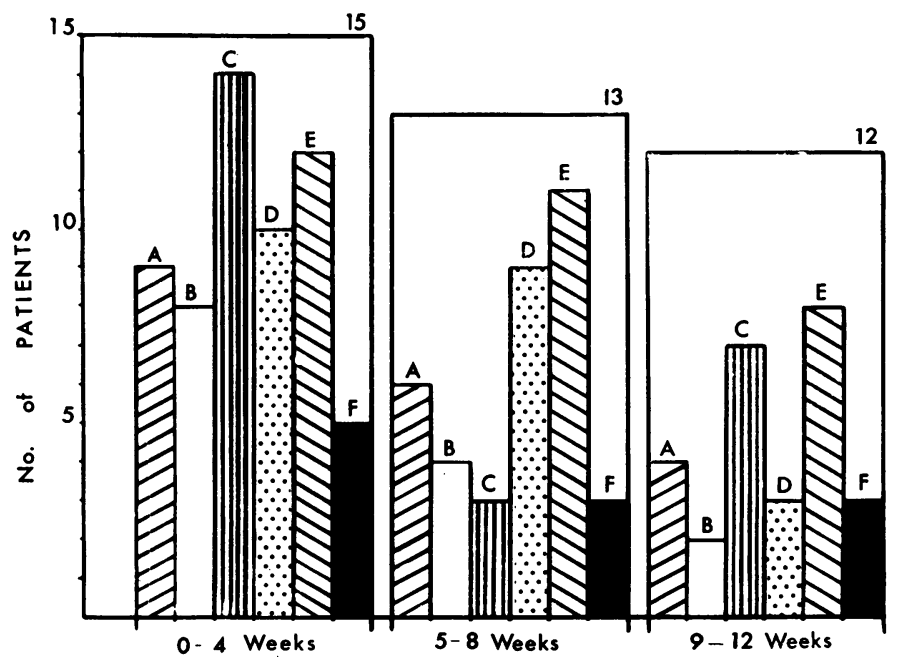

FIG.-Congenital defects correlated with time of maternal rubella infection. $A=$ low birthweight or neonatal purpura, $\mathrm{\omega}$ $B=$ congenital heart disease, $C=$ ocular defect, $D=$ rubella chorioretinopathy, $E=$ deafness, $F=$ central nervous system involvement.

$\mathrm{p}<0.025)$, and the proportion with severe mental deficiency $\left(\chi^{2}=10 \cdot 6, \mathrm{p}<0.005\right)$.

Closer comparison reveals that the younger children had more defects per patient, i.e. were more severely affected, than the adult group. $62 \%$ of the adults had 2 or 3 defects, whereas $71 \%$ of the children had 4,5 , or 6 defects. It is possible that better medical care in their early years had allowed more of these severely affected children to survive than in the adult group.

Earlier diagnosis and treatment of defects was a feature of the younger group-more deaf children were detected in the first year of life, speech therapy was started earlier, and cardiac defects were treated earlier than in the adult group.

\section{TABLE III}

Manifestations of Congenital Rubella in 41 Children, Compared with 50 Adults

\begin{tabular}{|c|c|c|c|c|c|c|}
\hline & & & \multicolumn{2}{|c|}{ Children } & \multicolumn{2}{|c|}{ Adults } \\
\hline & & & No. & $\%$ & No. & $\%$ \\
\hline $\begin{array}{ll}\text { Low birthweight } & \ldots \\
\text { Small stature } & \ldots \\
\text { Ocular defect } & \ldots \\
\text { Deafness .. } & \ldots \\
\text { Congenital heart disease } \\
\text { Mental deficiency } & \text {. } \\
\text { Skeletal defect } & \text {. } \\
\text { Undescended testes } \\
\text { Diabetes mellitus ... }\end{array}$ & $\begin{array}{l}\cdots \\
\cdots \\
\cdots \\
\cdots \\
\cdots \\
\cdots \\
\cdots \\
\cdots\end{array}$ & $\begin{array}{l}\cdots \\
\cdots \\
\cdots \\
\cdots \\
\cdots \\
\cdots \\
\cdots \\
\cdots\end{array}$ & $\begin{array}{c}17 \\
22 \\
37 \\
31 \\
15 \\
10 \\
27 \\
4 / 16 \\
2\end{array}$ & $\begin{array}{r}41 \\
54 \\
90 \\
76 \\
37 \\
24 \\
66 \\
25 \\
5\end{array}$ & $\begin{array}{c}18 \\
25 \\
28 \\
48 \\
11 \\
1 \\
20 \\
6 / 22 \\
1\end{array}$ & $\begin{array}{r}36 \\
50 \\
56 \\
96 \\
22 \\
2 \\
40 \\
27 \\
2\end{array}$ \\
\hline
\end{tabular}

\section{Discussion}

This study provides a picture of congenital rubella in children of school age and adolescenes. The only group studied similar in age is that $\$ \mathrm{f}^{\circ}$ Sever and Monif (1965).

The striking feature of this study was the multip city of defects. $88 \%$ had multiple defects. In a review of 120 cases from The Hospital for Sick Children, Dudgeon (1967) found 79\% with multiple $\stackrel{\propto}{\perp}$ defects; while of Alford's (1968) 141 cases $92 \%$ had multiple defects. Ocular defects and deafness, 3 seen in 13 patients, was the most common double defect as in Alford's group (1968). This highọ incidence of multiple defects can only be partly explained by an intentional search for additionalo defects-if the rubella virus has the widespreadoendothelial predilection in the fetus that we believe, 3 . it is not surprising to find several systems involved. 8

The incidence of low birthweight with normal gestational age $(41 \%)$ is similar to the over-allo incidence of $50 \%$ after the 1964 U.S.A. epidemic (Dudgeon, 1967). Those children with low birth-0․․ weights tended to have small statures later, con firming the findings of Lundström (1962) and Menser et al. (1967). However, the low birthweight did not affect prognosis for mental development N. The findings of only two patients with neonatalo purpura contrasts sharply with the high incidence (35\%) following the 1964 U.S.A. epidemic (Cooper et al., 1965). Postnatal rubella, such as was reported? in 13 of our 41 children, has been previouslyo 
documented in congenital rubella (Doege and Kim, 1967; Kenrick et al., 1968).

In this series, there was no correlation between the timing of the attack of maternal rubella, and the severity of the fetal defects. There were no cases of maternal infection after the third month. However, cases of maternal rubella in the second and third trimesters causing multiple defects have been reported by Hardy (1968) and Alford (1968). The traditional concept of cataract and heart involvement following maternal rubella in the first 8 weeks, and deafness following maternal rubella after 8 weeks (Gregg, 1941; Cooper and Krugman, 1967) is not borne out in this series.

A definite 'rubella personality' postulated by others (Robbins and Stenquist, 1967) could not be delineated in this group. Most children had warm and affectionate relationships with their mothers, and the ability of most of the mothers to cope with the problems of the various defects and to relate to their children was impressive.

One of us (J.M.F.) is supported by a Grant-in-aid from the National Heart Foundation of Australia.

We are grateful to Dr. R. Hertzberg, Honorary Ophthalmic Surgeon, Royal Alexandra Hospital for Children; to Mr. William Engel, Secretary-superintendent, Adult Deaf and Dumb Society of N.S.W.; and to Mr. Douglas B. Fifield, psychologist, Commonwealth Acoustic Laboratory, Sydney.

\section{REFERENCES}

Alford, B. R. (1968). Rubella - la bête noire de la médecine. Laryngoscope, 78, 1623.

Australian Institute of Anatomy. (1957). Standard Height-Weight Tables for Australians. Department of Health, Canberra.
Cooper, L. Z., Green, R. H., Krugman, S., Giles, J. P., and Mirick, G. S. (1965). Neonatal thrombocytopenic purpura and other manifestations of rubella contracted in utero. American Fournal of Diseases of Children, 110, 416.

, and Krugman, S. (1967). Clinical manifestations of postnatal and congenital rubella. Archives of Ophthalmology, 77, 434.

Dods, L. (1951). Stillbirths and congenital malformations follow ing rubella and other virus diseases during pregnancy. In Modern Trends in Pediatrics. 1st. ser., p. 1. Ed. by Sir L. Parsons. Butterworth, London.

Doege, T. C., and Kim, K. S. W. (1967). Studies of rubella and its prevention with immune globulin. Fournal of the American Medical Association, 200, 584.

Dudgeon, J. A. (1967). Maternal rubella and its effect on the foetus. Archives of Disease in Childhood, 42, 110.

Forrest, J. M., Menser, M. A., and Harley, J. D. (1969). Diabetes mellitus and congenital rubella. Pediatrics, 44, 445.

Gregg, N. M. (1941). Congenital cataract following German measles in the mother. Transactions of the Ophthalmological Society of Australia, 3, 35.

Hardy, J. B. (1968). Viruses and the fetus. Postgraduate Medicine, 43, 156.

Keir, E. H. (1965). Results of rubella in pregnancy. II. Hearing defects. Medical fournal of Australia, 2, 691.

Kenrick, K. G., Slinn, R. F., Dorman, D. C., and Menser, M. A. (1968). Immunoglobulins and rubella-virus antibodies in adults with congenital rubella. Lancet, 1, 548.

Lundström, R. (1962). Rubella during pregnancy. A follow-up study of children born after an epidemic of rubella in Sweden, 1951. Acta Paediatrica, 51, suppl. 133.

Menser, M. A., Dods, L., and Harley, J. D. (1967). A twentyfive-year follow-up of congenital rubella. Lancet, 2, 1347.

Purvis-Smith, S. G., and Menser, M. A. (1968). Dermatoglyphics in adults with congenital rubella. Lancet, 2, 141.

Robbins, N., and Stenquist, G. (1967). The Deaf-Blind 'Rubella' Child. Perkins Publication No. 25, Watertown, Mass., U.S.A.

Sever, J. L., and Monif, G. (1965). Limited persistence of virus in congenital rubella. American fournal of Diseases of Children, $110,452$.

Correspondence to Dr. Jill M. Forrest, P.O. Box 34, Camperdown, N.S.W. 2050, Australia. 